Research Article

\title{
Design of Broadband Band-Pass Filter with Cross-Coupled Line Structure
}

\author{
Dong-Sheng La $\mathbb{D}^{1,2}{ }^{1,2}$ Xin Guan, ${ }^{1}$ Hong-Cheng $\mathrm{Li}^{,}{ }^{1}$ Yu-Ying Li, ${ }^{1}$ and Jing-Wei Guo ${ }^{3}$ \\ ${ }^{1}$ School of Computer and Communication Engineering, Northeastern University at Qinhuangdao, Qinhuangdao 066004, China \\ ${ }^{2}$ Guangxi Key Laboratory of Wireless Wideband Communication and Signal Processing, Guilin 541004, China \\ ${ }^{3}$ School of Information Science and Engineering, Yanshan University, Qinhuangdao 066004, China
}

Correspondence should be addressed to Dong-Sheng La; ladongsheng@163.com

Received 22 May 2020; Revised 1 July 2020; Accepted 13 July 2020; Published 27 July 2020

Academic Editor: Atsushi Mase

Copyright (c) 2020 Dong-Sheng La et al. This is an open access article distributed under the Creative Commons Attribution License, which permits unrestricted use, distribution, and reproduction in any medium, provided the original work is properly cited.

\begin{abstract}
This paper presents a broadband band-pass filter with cross-coupled line structure. The cross-coupled line structure is composed of the parallel coupled lines and an open stub. It can be analyzed by the odd- and even-mode method due to its symmetric structure. There are three transmission poles in the passband and two transmission zeros out of passband. Then, the influence of the impedance parameters on the transmission zeros and transmission poles are analyzed. Then, the physical parameters of the proposed band-pass filter are given. And using HFSS for simulation and optimization, the final insertion loss and return loss of filter are obtained. The simulation and measurement results are in good agreement, which validates the design idea.
\end{abstract}

\section{Introduction}

Band-pass filters (BPFs) with high frequency selectivity and out-of-band rejection levels are intensively required in the modern wireless communication systems. Resonators are usually proposed to construct wideband BPFs. Wang introduced a cross-shaped resonator with wide passband. By cascading two cross-shaped resonator structures, a compact ultrawideband band-pass filter is designed [1]. The performance of the wideband BPF need to be improved. Xu proposed a broadband band-pass filter composed of the coupled lines and a cross-shaped resonator, which improves the frequency selection characteristics of the band-pass filter by introducing a transmission zero point [2]. In [3], a novel band-pass filter with a $T$-shaped structure is proposed. The position of the transmission zeros can be adjusted to achieve high selectivity of the band-pass filter. Cheng proposed a broadband band-pass filter based on parallel coupled lines and cross-shaped resonators. The p-i-n diodes are used as the tuning elements, which can implement three reconfigurable bandwidth states [4]. In [5], the filter is based on the cross-shaped resonator structure with terminal short circuit. The low-frequency band of the first passband can be adjusted by the capacitance value, while the other three band edges remain unchanged. In $[6,7]$, a cross-shaped resonator with an open stub is used to design a band-pass filter and a cross-coupled stub is used to design a microstrip band-stop filter. Most filter structures are complex and difficult to be analyzed and discussed. Some filters are difficult to give an equivalent circuit for analysis. In addition, most filters require high manufacturing accuracy.

In this letter, a wideband BPF based on a novel single cross-coupled line resonator is presented. The equivalent circuit of the proposed BPF is given and the performance of the proposed filter is analyzed. Based on filter's design index, the appropriate impedance parameters and the physical sizes of the microstrip lines can be obtained. Section 2 introduces the structure of proposed cross-coupled line structure with transmission poles and transmission zeros analysis. In 


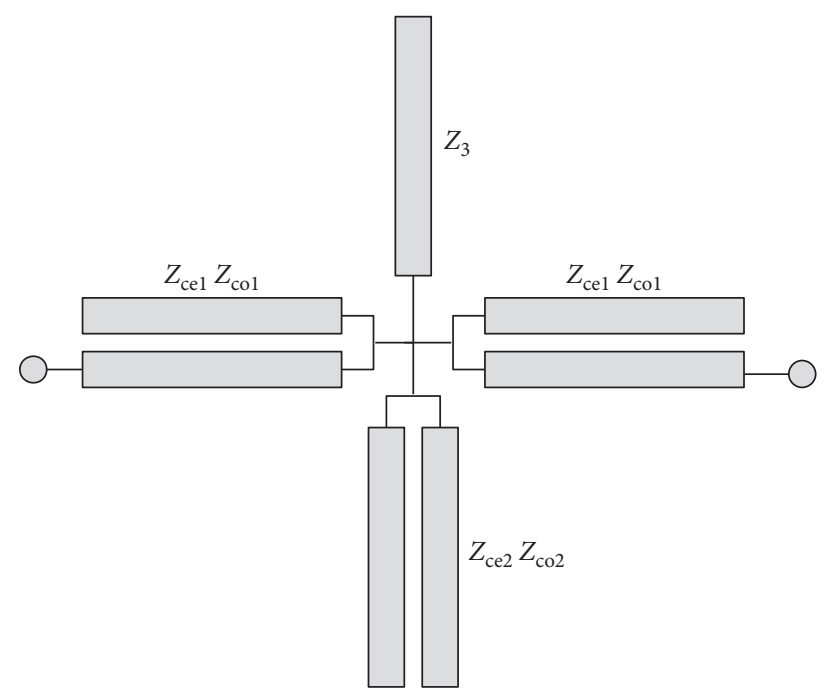

(a)

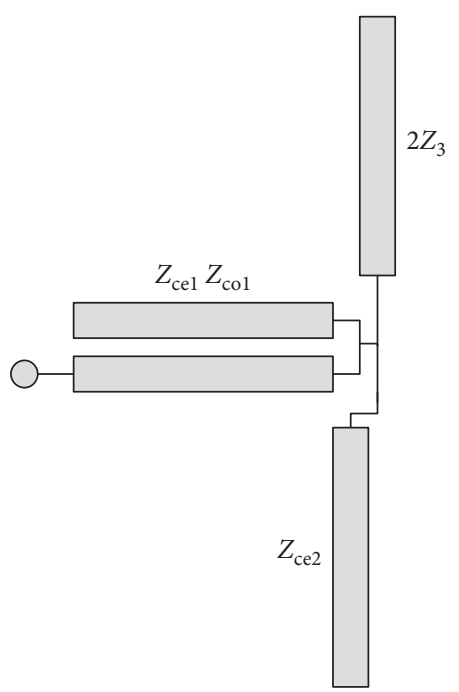

(b)

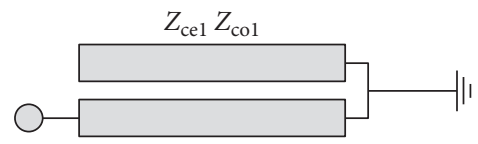

(c)

FIGURE 1: Ideal circuit of wideband BPF and its equivalent circuit model: (a) ideal circuit model; (b) odd-mode circuit; (c) even-mode circuit.

Section 3, the simulated and measured results of the fabricated BPF are shown. The conclusion is summarized in Section 4.

\section{Filter Analysis and Design}

The ideal circuit of the proposed wideband BPF with three transmission poles, which consists of parallel coupled lines and one branch microstrip line, is shown in Figure 1(a). The odd-mode and even-mode equivalent circuits are shown in Figures 1(b) and 1(c), respectively. For the convenience of calculation, the impedance values use the normalized impedances.

The odd-mode equivalent circuit and the even-mode equivalent circuit have the same coupling structure. It can be seen as an equivalent circuit where the load takes different values, as shown in Figure 2 . Let $i_{2}=0,-i_{4}=i_{3}+i_{L}$, and $v_{3}=-i_{L} z_{L}$ be brought into equations (1a) and (1b). Equation (2) can be obtained:

$$
\begin{aligned}
& {\left[\begin{array}{c}
v_{1}-v_{2} \\
i_{1}-i_{2}
\end{array}\right]=\left[\begin{array}{cc}
\cos \theta & j Z_{\mathrm{co}} \sin \theta \\
j Y_{\mathrm{co}} \sin \theta & \cos \theta
\end{array}\right]\left[\begin{array}{c}
v_{4}-v_{3} \\
-\left(i_{4}-i_{3}\right)
\end{array}\right],} \\
& {\left[\begin{array}{c}
v_{1}+v_{2} \\
i_{1}+i_{2}
\end{array}\right]=\left[\begin{array}{cc}
\cos \theta & j Z_{\mathrm{ce}} \sin \theta \\
j Y_{\mathrm{ce}} \sin \theta & \cos \theta
\end{array}\right]\left[\begin{array}{c}
v_{4}+v_{3} \\
-\left(i_{4}+i_{3}\right)
\end{array}\right],}
\end{aligned}
$$

$$
z_{\text {ine }(o)}
$$$$
=\frac{z_{\mathrm{ce} 1} z_{\mathrm{Le}(o)}-z_{\mathrm{col} 1} \tan ^{2} \theta z_{\mathrm{Le}(o)}+(1 / 2) j \tan \theta+(1 / 2) j z_{\mathrm{cel}}^{2} \tan \theta}{2 j \tan \theta z_{\mathrm{Le}(o)}+z_{\mathrm{ce} 1}} .
$$
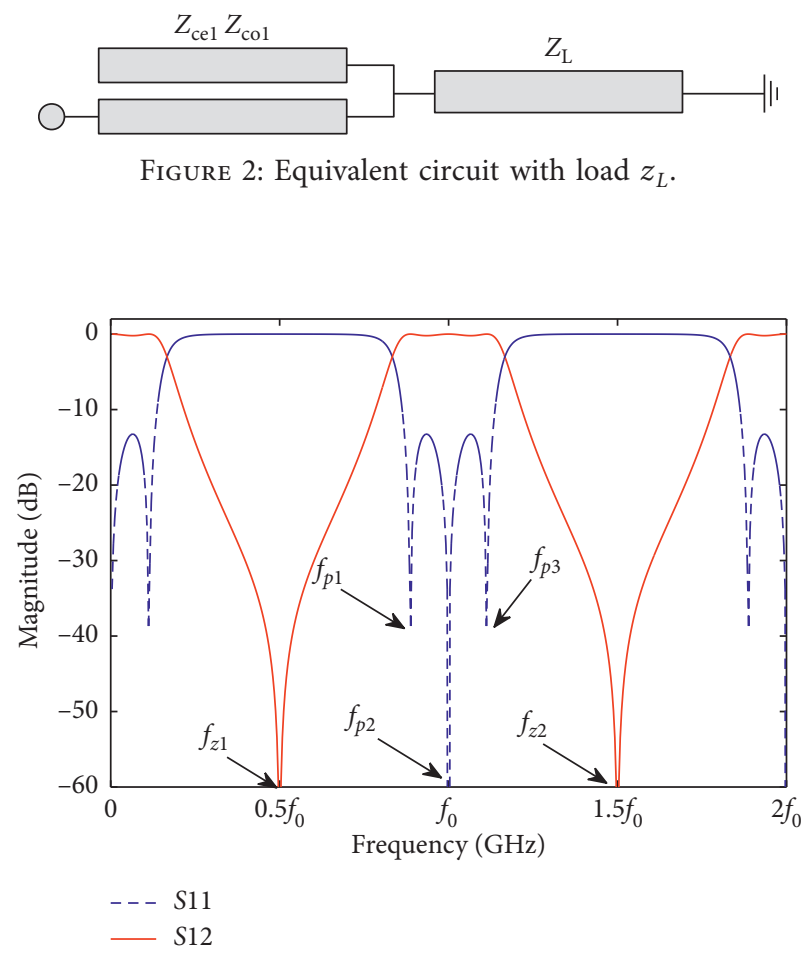

FIgURE 3: The calculated frequency responses for Figure 1(a).

In Figure 2, $z_{L}$ is the load impedance. According to the transmission line theory, the even and the odd-mode load impedance can be obtained as formulas (3) and (4), respectively: 

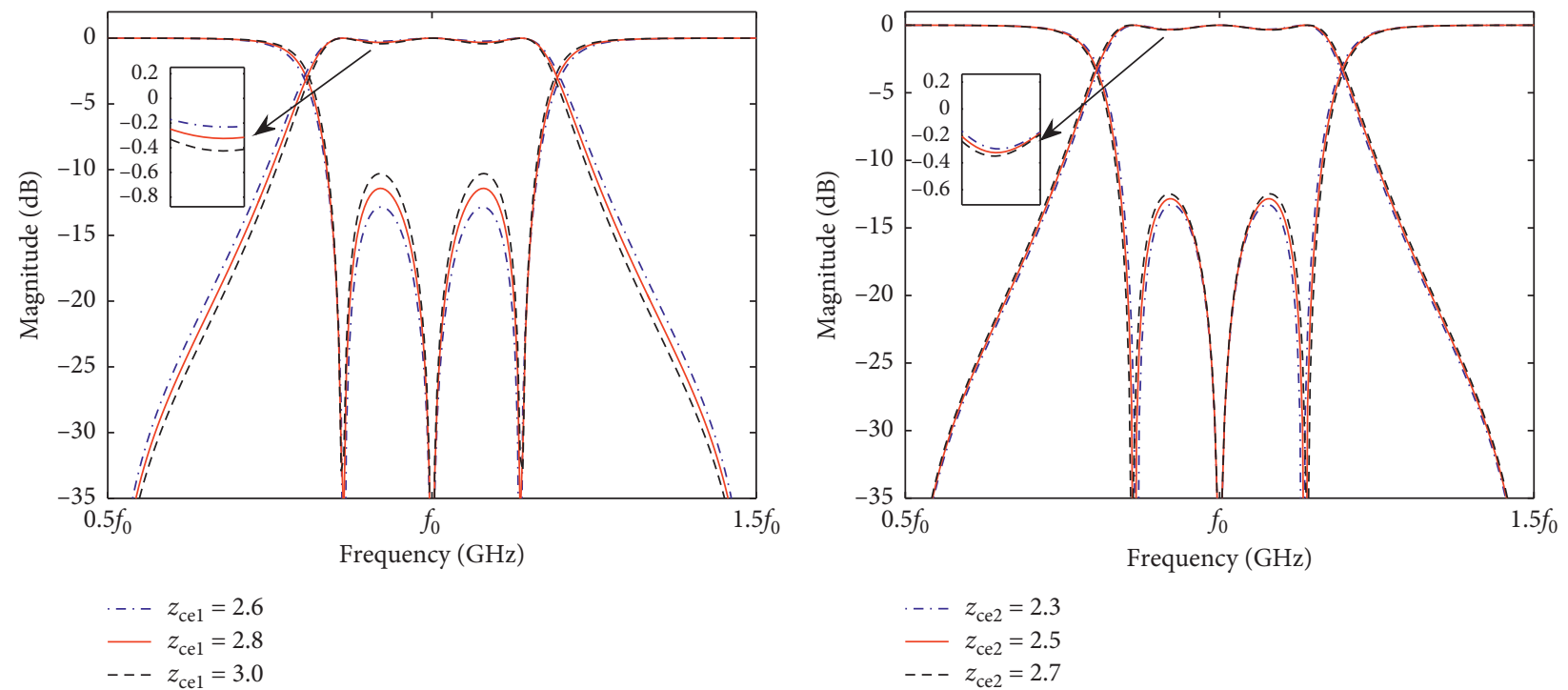

(a)

(b)

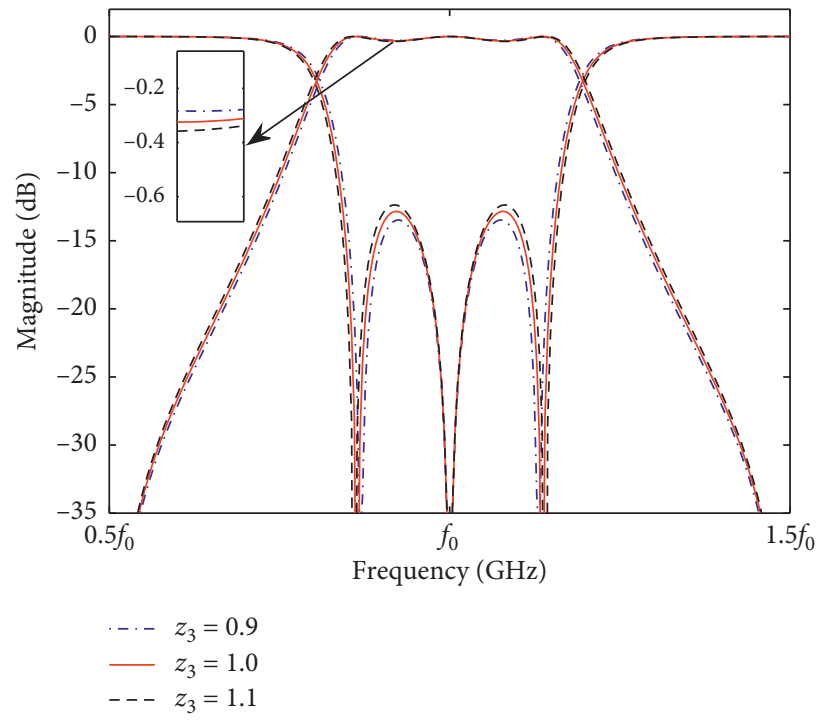

(c)

FIGURE 4: Simulated frequency responses of the proposed BPF with varied impedance parameters. (a) $z_{\mathrm{ce} 1}$, (b) $z_{\mathrm{ce} 2}$, and (c) $z_{3}$.

$$
\begin{gathered}
z_{\mathrm{Le}}=\frac{2 z_{3} z_{\mathrm{ce} 2}}{2 z_{3} j \tan \theta+z_{\mathrm{ce} 2} j \tan \theta}, \\
z_{\mathrm{Lo}}=0 .
\end{gathered}
$$

In a symmetric two-port network, the normalized frequency response is

$$
\begin{aligned}
& s_{11}=s_{22}=\frac{z_{\text {ine }} z_{\text {ino }}-1}{\left(z_{\text {ine }}-1\right)\left(z_{\text {ino }}-1\right)}, \\
& s_{12}=s_{21}=\frac{z_{\text {ine }}-z_{\text {ino }}}{\left(z_{\text {ine }}-1\right)\left(z_{\text {ino }}-1\right)} .
\end{aligned}
$$

The transmission zeros of the new structure will fulfill the conditions $\left|S_{21}\right|=0$, which corresponds to $z_{\text {ine }}=z_{\text {ino }}$ $\left(z_{\mathrm{Le}}=z_{\mathrm{Lo}}\right)$. The transmission zeros can be obtained as formulas (7) and (8). The broadband band-pass filter has two fixed transmissions:

$$
\begin{aligned}
& f_{z 1}=\frac{1}{2} f_{0}\left(\theta=\frac{\pi}{2}\right), \\
& f_{z 2}=\frac{3}{2} f_{0}\left(\theta=\frac{3 \pi}{2}\right) .
\end{aligned}
$$

By setting $\left|S_{11}\right|=0$, formula (9) can be obtained:

$$
\begin{array}{r}
-2\left(\left(z_{3}+\frac{1}{2} z_{\mathrm{ce} 2}\right) z_{\mathrm{ce} 1}^{2}+\left(\frac{1}{2}+2 z_{\mathrm{co} 1} z_{3}\right) z_{\mathrm{ce} 2}+z_{3}\right)\left(z_{\mathrm{ce} 1}^{2}+1\right) \tan ^{3} \theta \\
+4 z_{\mathrm{ce} 1}\left(z_{\mathrm{ce} 1}^{2} z_{3} z_{\mathrm{ce} 2}-\left(2 z_{3}+z_{\mathrm{ce} 2}\right) z_{\mathrm{ce} 1}-3 z_{\mathrm{ce} 2} z_{3}\right) \tan \theta=0 .
\end{array}
$$


By solving equation (9), it can be obtained that the bandpass filter has three transmission poles between $0.5 f_{0}$ and $1.5 f_{0}$ as follows:

$$
\begin{aligned}
& f_{p 1}=\frac{2 f_{0} \arctan \left(\sqrt{u_{p}}\right)}{\pi}, \\
& f_{p 3}=\frac{2 f_{0}\left(\pi-\arctan \left(\sqrt{u_{p}}\right)\right)}{\pi}, \\
& f_{p 2}=f_{0},
\end{aligned}
$$

where $u_{p}=\left(4 z_{c e 1}\left(z_{c e 1}^{2} z_{3} z_{c e 2}-\left(2 z_{3}+z_{c e 2}\right) z_{c e 1}-3 z_{c e 2} z_{3}\right)\right) /$ $\left(2\left(\left(2 z_{3}+z_{c e 2}\right) z_{c e 1}^{2}+\left(1+4 z_{c o 1} z_{3}\right) z_{c e 2}+z_{3}\right)\left(z_{c e 1}^{2}+1\right)\right)$.

According to the analysis above, the numbers and relative positions of the transmission poles and transmission zeros is shown in Figure 3. It is obvious that the proposed $\mathrm{BPF}$ has three transmission poles in the passband and two transmission zeros in the stopband. It can be verified mathematically that $f_{z 1}<f_{p 1}<f_{p 2}<f_{p 3}<f_{z 2}$.

Designing parameters is shown in Figure 4 . Under the basic design parameters of $z_{\mathrm{ce} 1}=2.8, z_{\mathrm{ce} 2}=2.5$, and $z_{3}=1$. With the changes of $z_{\mathrm{ce} 1}$ and $z_{c e 2}$, the positions of the transmission poles do not change significantly. Figure 4(c) shows that the transmission poles $f_{p 1}$ and $f_{p 3}$ get away from center frequency $f_{0}$ when $z_{3}$ increases. The proposed filter bandwidth increases. Furthermore, the return loss in the passband changes with the changes of the normalized impedance parameters.

The small change of the impedance parameters has little effect on the performance of the proposed BPF. Therefore, processing errors, small error in the dielectric constant, and thickness have little effect on the filter performance.

\section{Filter's Results and Discussion}

The proposed BPF is designed on Rogers RT5880 microwave dielectric board $\left(h=0.508 \mathrm{~mm}, \varepsilon_{\mathrm{re}}=2.2, \tan \delta=0.0009\right)$, where $f_{0}$ is $4.3 \mathrm{GHz}$. Based on the impedance parameters $z_{\mathrm{ce} 1}=2.8, z_{\mathrm{ce} 2}=2.5$, and $z_{3}=1$, the theoretical physical dimensions are calculated by ADS LineCalc. Next, slight adjustment and optimization needs to be further conducted in the HFSS in order to compensate the open ports and dissipation effect of microstrip lines. The final dimensions of the proposed BPF for fabrication are shown in Figure 5 $(a=0.22 \mathrm{~mm}, \quad b=0.16 \mathrm{~mm}, \quad c=1.8 \mathrm{~mm}, \quad d=10 \mathrm{~mm}$, $r=16.5 \mathrm{~mm}, \quad m=0.2 \mathrm{~mm}, \quad n=0.2 \mathrm{~mm}, \quad t=14.9 \mathrm{~mm}$, $p=11 \mathrm{~mm}, h=5 \mathrm{~mm}, w=1.54 \mathrm{~mm}, s=14.8 \mathrm{~mm}$, and $e=11.4 \mathrm{~mm})$.

The measured S-parameters is plotted in Figure 6 along with the simulated results using Ansys HFSS for comparisons. The simulated and measured results display a good agreement. The measured $3-\mathrm{dB}$ bandwidth is $1.8 \mathrm{GHz}$ from $3.4 \mathrm{GHz}$ to $5.2 \mathrm{GHz}$, representing a FBW of $42 \%$ at the center frequency of $4.3 \mathrm{GHz}$. The insertion loss at $4.3 \mathrm{GHz}$ is $0.7 \mathrm{~dB}$, and the return loss is better than $15 \mathrm{~dB}$ across the desired passband. Furthermore, the insertion loss is over $20 \mathrm{~dB}$ at upper stopband from $5.3 \mathrm{GHz}$ to $7.5 \mathrm{GHz}$ and the insertion

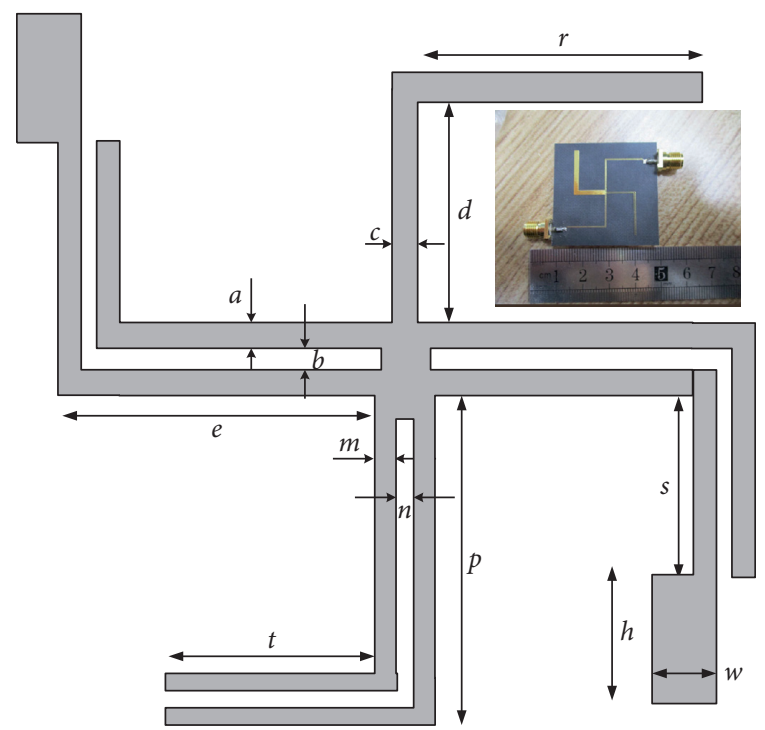

FIgURE 5: Physical layout for the proposed BPF and photograph of the proposed BPF (dimensions in $\mathrm{mm}$ ).

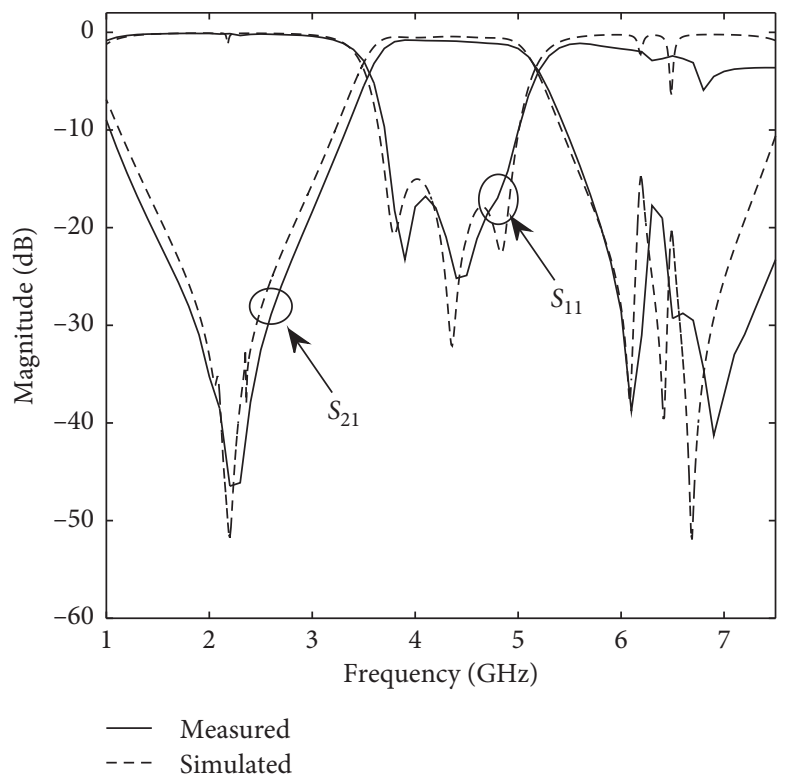

Figure 6: Simulated and measured S-parameters of the proposed BPF.

loss is better than $10 \mathrm{~dB}$ at lower stopband from $1 \mathrm{GHz}$ to 3.4 GHz.

Table 1 compared our work with some previous works, and it can be seen that the presented study has compact structure, good in-band characteristics, and better frequency selectivity. The proposed BPF is composed of a single coupled line cross-shaped resonator. Compared with the original cross-shaped resonator filter, the coupled line crossshaped resonator filter has better frequency selectivity, passband, and stopband performance. Compared with complex resonator combination structure, the coupled line cross-shaped resonator structure is simple and convenient for theoretical analysis and production. 
TABLE 1: Comparisons with some previous BPFs.

\begin{tabular}{lcccccccc}
\hline Ref & $\begin{array}{c}\text { Passband } \\
\text { bandwidth } \\
(\mathrm{GHz})\end{array}$ & $\begin{array}{c}-10 \mathrm{~dB} \text { lower } \\
\text { stopband bandwidth } \\
(\mathrm{GHz})\end{array}$ & $\begin{array}{c}-10 \mathrm{~dB} \text { upper } \\
\text { stopband bandwidth } \\
(\mathrm{GHz})\end{array}$ & $\begin{array}{c}\mathrm{RL} \\
(\mathrm{dB})\end{array}$ & $\begin{array}{c}\mathrm{IL} \\
(\mathrm{dB})\end{array}$ & $\begin{array}{c}\text { Size } \\
\left(\lambda_{g} * \lambda_{g}\right)\end{array}$ & $\begin{array}{c}\text { Transition } \\
\text { band }(\mathrm{GHz})\end{array}$ & $\begin{array}{c}\text { Circuit } \\
\text { complexity }\end{array}$ \\
\hline$[1]$ & 7.3 & 2.5 & 5 & 20 & 0.35 & $0.5 * 0.79$ & $0.5 / 0.7$ & Simple \\
{$[6]$} & 0.19 & 0.4 & 0.4 & 16 & 1.28 & $0.18 * 0.175$ & $0.08 / 0.08$ & Simple \\
{$[8]$} & 8 & 2.3 & 2.8 & 10 & 0.52 & $0.1 * 0.1$ & $0.15 / 0.15$ & Complex \\
{$[9]$} & 4.15 & 2.2 & 2.5 & 15 & 1.45 & $0.5 * 0.04$ & $0.45 / 0.5$ & Complex \\
This work & 1.8 & 2.0 & 15 & 0.7 & $0.12 * 0.14$ & $0.3 / 0.3$ & Simple \\
\hline
\end{tabular}

Note: RL (return loss in passband); IL (insertion loss in passband); transition band is in the frequency range from $-3 \mathrm{~dB}$ to $-10 \mathrm{~dB}$.

\section{Conclusions}

This paper presents a BPF with cross-shaped coupled line structure. With the use of even and odd-mode approach, the filter's parameters have a little effect on the resonant characteristics of the proposed BPF. Therefore, the manufacturing error, small changes in the dielectric constant, and thickness have a small effect on the filter's performance. The synthesized, simulated results agree well with the measured results, thus evidently verifying the validity of the proposed synthesis approach.

\section{Data Availability}

The data used to support the findings of this study are included within the article.

\section{Conflicts of Interest}

The authors declare that they have no conflicts of interest.

\section{Acknowledgments}

This work was supported by the National Natural Science Foundation of China under Grant 61501100, Natural Science Foundation of Hebei Province under Grant F2019203012, Fundamental Research Funds for the Central Universities under Grant N2023017, and Open Project of Guangxi Key Laboratory of Wireless Wideband Communication and Signal Processing under Grant GXKL06180201.

\section{References}

[1] H. Wang, G. Yang, W. Kang, C. Miao, and W. Wu, "Application of cross-shaped resonator to the ultra wideband bandpass filter design," IEEE Microwave and Wireless Components Letters, vol. 21, no. 12, pp. 667-669, 2011.

[2] K. D. Xu, F. Zhang, Y. Liu, and W. Nie, "High selectivity seventh-order wideband bandpass filter using coupled lines and open/shorted stubs," Electronics Letters, vol. 54, no. 4, pp. 223-225, 2018.

[3] K. D. Xu, S. Lu, and Y. Ren, "Coupled-line band-pass filter with $T$-shaped structure for high frequency selectivity and stopband rejection," International Journal of RF and Microwave Computer-Aided Engineering, vol. 28, no. 9, 2020.

[4] T. Cheng and K.-W. Tam, "A wideband bandpass filter with reconfigurable bandwidth based on cross-shaped resonator,"
IEEE Microwave and Wireless Components Letters, vol. 27, no. 10, pp. 909-911, 2017.

[5] X.-K. Bi, T. Cheng, P. Cheong, S.-K. Ho, and K.-W. Tam, "Design of dual-band bandpass filters with fixed and reconfigurable bandwidths based on terminated cross-shaped resonators," IEEE Transactions on Circuits and Systems II: Express Briefs, vol. 66, no. 3, pp. 317-321, 2019.

[6] Z. C. Guo, L. Zhu, and S. W. Wong, "A quantitative approach for direct synthesis of band-pass filters composed of transversal resonators," IEEE Transactions on Circuits and Systems II: Express Briefs, vol. 66, no. 4, pp. 577-581, 2019.

[7] L. Chiu and Q. Xue, "A simple microstrip bandstop filter using cross-coupling stubs," International Journal of Microwave Science and Technology, vol. 2012, Article ID 473030, 6 pages, 2012.

[8] H. Wang, W. Kang, C. Miao, and W. Wu, "Cross-shaped UWB bandpass filter with sharp skirt and notched band," Electronics Letters, vol. 48, no. 2, 2012.

[9] W. J. Feng and W. Q. Che, "Wideband balanced bandpass filter based on three-line coupled structure"' Electronics Letters, vol. 48 , no. 16, 2012. 